\title{
A Coherent Mechanistic Rationale for Additive Effects and Autoinductive Behavior in Proline-Mediated Reactions
}

\author{
Natalia Zotova, ${ }^{\mathrm{a}}$ Antonio Moran, ${ }^{\mathrm{b}}$ Alan Armstrong ${ }^{\mathrm{b} *}$, and Donna G. Blackmond ${ }^{\mathrm{a}, \mathrm{b} *}$ \\ a Department of Chemical Engineering \& Chemical Technology, Imperial College London SW7 2AZ \\ b Department of Chemistry, Imperial College London SW7 2AZ a.armstrong@imperial.ac.uk, \\ d.blackmond@imperial.ac.uk, Fax +44 (0)20 75945804
}

\begin{abstract}
Differences in the kinetic behavior of aldol reactions compared to aminoxylation and amination reactions are rationalized by consideration of the ratedetermining step in each case. Both autoinductive behavior and the rate-enhancing effect of additives are attributed to an effect on the enamine formation step.
\end{abstract}

Keywords: organocatalysis $\cdot$ kinetics $\cdot$ autoinduction · amino acid catalysis $\cdot$ reaction mechanism

Proline catalysis, elegantly revived by List, Lerner and Barbas in 2000 [1], has demonstrated efficient and enantioselective carbon-carbon and carbonheteroatom bond-forming reactions, including those shown in eq. 1, and has inspired the development of many other catalysts for a myriad of selective transformations [2]. Computational studies [3] have suggested a mechanistic analogy to reactions of aldolase enzymes [4]. Our recent work provided the first kinetic support for the enamine mechanism in aldol reactions and clarified the role of water on and off the catalytic cycle $[5,6]$.

$$
\text { PhNO }
$$

A number of intriguing experimental observations have yet to be rationalized for these reactions. One unusual feature is a striking temporal increase in reaction rate that is observed in the $\alpha$-aminoxylation
$[7,8]$ (eq 1a) and $\alpha$-amination of aldehydes $[9,10]$ (eq $1 \mathrm{~b}$ ), but is not observed in aldol reactions (eq 1c). In addition, additives including acids and bases have been observed to influence reactions employing proline as well as other pyrrolidine-based catalysts $[11,12]$. Here we present kinetic results that offer a coherent mechanistic rationalization for both the role of additives and the autoinductive behavior in proline-mediated reactions. These findings suggest an important role for detailed kinetic analysis in understanding and improving catalyst efficiency.

The autoinductive behavior observed in the reactions of eqs $1 \mathrm{a}$ and $1 \mathrm{~b}$ suggests that the product plays a role in accelerating rate, as is confirmed in Figure 1 for addition of product $3 \mathbf{b}$ to the $\alpha$ amination reaction of eq $1 \mathrm{~b}$. The figure also shows that addition of aldol product 7 to the aldol reaction of eq 1c has no influence on the rate of this reaction.

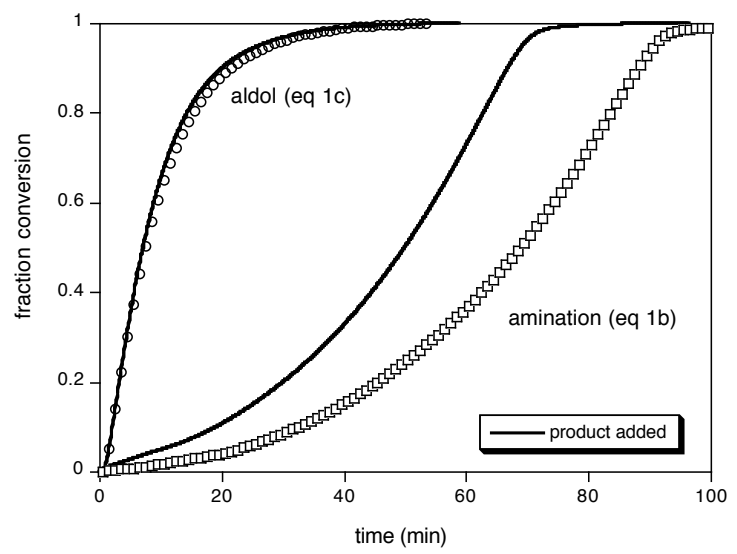

Figure 1. Effect of the addition of amination reaction product $\mathbf{3 b}$ ( 0.2 equiv) or aldol product 7 (1.1 equiv) to the reactions of eqs $1 \mathrm{~b}$ or $1 \mathrm{c}$, respectively. Open symbols: reaction without added product; solid lines: reaction with added product. 
The two reactions exhibit distinctly different kinetic profiles, with the aldol reaction characterized by well-behaved positive order kinetics while the reactions of eqs $1 \mathrm{a}-1 \mathrm{~b}$ show the sigmoidal conversion profile characteristic of an autoinductive process. Product ee is unaffected by added product in either reaction. The reactions of eqs. $1 \mathrm{a}$ and $1 \mathrm{~b}$ do not proceed in the in the presence of product and absence of proline, confirming that the reactions are productaccelerated, or autoinductive, but not truly autocatalytic [14]. Careful studies, including those using fully soluble proline derivatives, showed that the effect could not be attributed to increasing solubilization of proline as the reaction proceeds [13].

Interestingly, however, our further studies show that the source of the rate enhancement in the reactions of eqs $1 \mathrm{a}$ and $1 \mathrm{~b}$ is not limited to the product specific to that reaction: Figure 2 shows that reaction rate in the fully homogeneous [15] $\alpha$ aminoxylation reaction of eq $1 \mathrm{a}$ is also strongly enhanced by addition of aldol product 7. A gradual shift away from the autoinductive kinetic profile was observed as the concentration of added 7 was increased (Figure 2a).
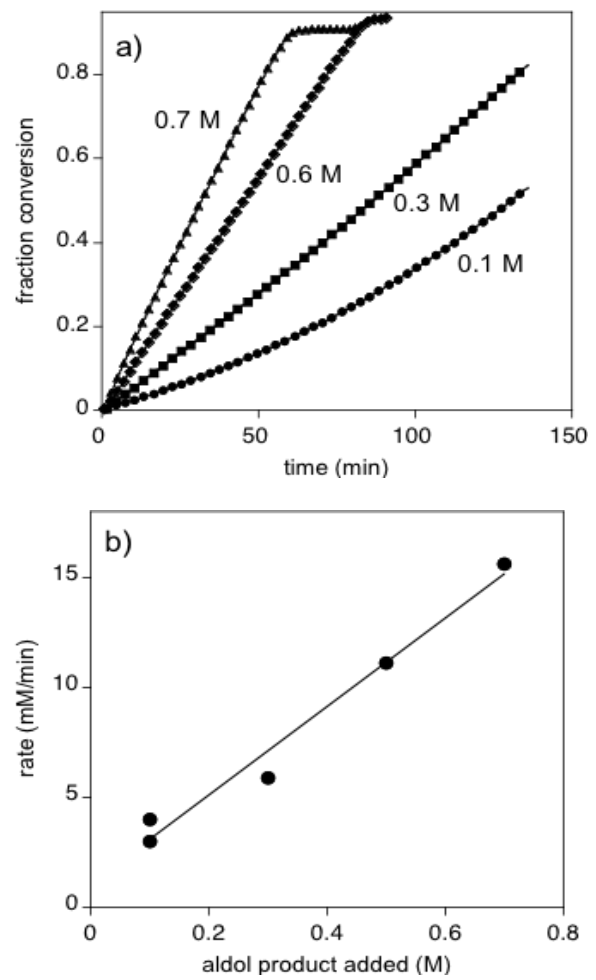

Figure 2. Fraction conversion vs time for the aminoxylation reaction of eq 1a with $2 \mathrm{M} \mathrm{1,} 0.5 \mathrm{M} \mathrm{2,} 0.04$ M 4 and added aldol product 7 in $\mathrm{CHCl}_{3}$ under homogeneous conditions [15]. a) conversion vs time for added [7] as noted; b) initial rate constant vs. added [7]. Product ee $97-98 \%$.

A similar influence on rate and rate profile was observed with additives ([add]) such as $\mathrm{CH}_{3} \mathrm{OH}$ and
$\mathrm{CH}_{3} \mathrm{COOH}$, where rate appears to saturate as [add] reaches higher concentrations (Figure 3) [16,17]. By contrast, the aldol reaction of eq $1 \mathrm{c}$ showed neither rate enhancement nor a change in the kinetic profile for reactions with any of these additives (see Supporting Information).
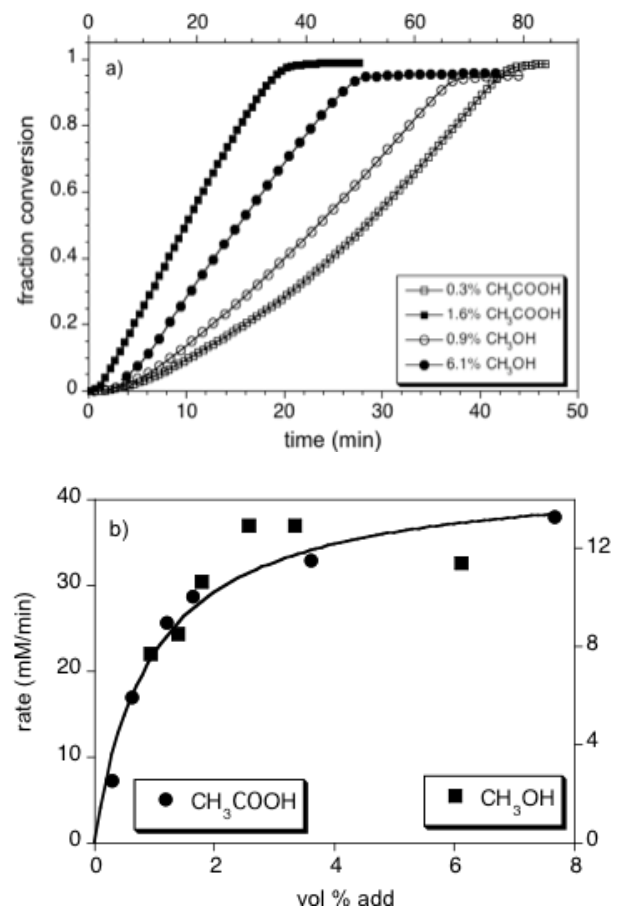

Figure 3. $\mathrm{CH}_{3} \mathrm{OH}$ or $\mathrm{CH}_{3} \mathrm{COOH}$ added to the aminoxylation reaction of eq 1a; $2 \mathrm{M} \mathrm{1,0.5} \mathrm{M} \mathrm{2a,} 0.04 \mathrm{M}$ 4 and $\mathrm{CH}_{3} \mathrm{OH}$ or $\mathrm{CH}_{3} \mathrm{COOH}$ as [add] in $\mathrm{CHCl}_{3}$ under homogeneous conditions [15] a) conversion vs. time (upper time axis for $\mathrm{CH}_{3} \mathrm{OH}$ ); b) rate vs. [add]; left axis: $\mathrm{CH}_{3} \mathrm{COOH}$; right axis: $\mathrm{CH}_{3} \mathrm{OH}$. Product ee $96-98 \%$ in all cases; conversion is quantitative in all cases.

These results show that rate in reactions $1 \mathrm{a}$ and $1 \mathrm{~b}$ is proportional to the concentration of the rateenhancing species, be it the reaction's own product or an additive. In the case of the reaction product, the autoinductive profile observed may thus be attributed to the reaction progress: the temporal enhancement in rate results from the increasing reaction product concentration over time. In the case where a species such as $\mathrm{CH}_{3} \mathrm{OH}$ or $\mathrm{CH}_{3} \mathrm{COOH}$ is added at a fixed concentration, this rate-enhancing effect of the reaction's own product competes with a similar effect of the additive. At higher additive concentrations, the influence of the additive begins to dominate, resulting in a shift away from the autoinductive kinetic profile. This suggests that a single mechanistic rationalization may explain both the autoinductive profile and the rate-enhancing effect of additives for the reactions of eqs $1 \mathrm{a}$ and $1 \mathrm{~b}$. Since these reactions are thought to proceed by a pathway similar to that of the aldol reaction of eq $1 \mathrm{c}$, such a rationale should also be able 
to account for the lack of effect of additives on rate in the aldol reaction.

The generally accepted mechanism for the reactions of eq 1 involves nucleophilic attack of proline on the carbonyl compound to form an enamine, followed by its attack on an electrophile $\mathbf{E}$, and finally hydrolysis to form the product. The intrinsic kinetic dependences of substrate concentrations for the reactions of eq. 1 may be compared in the context of this mechanism. We have shown that the aldol reaction of eq $1 \mathrm{c}$ exhibits a positive rate dependence on the concentrations of both substrates acetone $\mathbf{5}$ and aldehyde $\mathbf{6}$ and a negative order in $\left[\mathrm{H}_{2} \mathrm{O}\right]$, implicating rate-determining attack of enamine $\mathbf{9}$ on electrophile $\mathbf{6}$ for the intermolecular aldol reaction, with the further suggestion that the enamine formation steps are in pre-equilibrium (saturation kinetics in [9]) [5,6]. The reactions of eqs $1 \mathrm{a}$ and $1 \mathrm{~b}$, by contrast, exhibit zero order kinetics in concentration of the highly active electrophiles $\mathbf{2 a}$ and $\mathbf{2 b}$ and first order dependence on the concentration of the carbonyl substrate 1 [13], dependences that hold in the presence of additives such as $\mathrm{CH}_{3} \mathrm{OH}$ and $\mathrm{CH}_{3} \mathrm{COOH}$. Thus for reactions $1 \mathrm{a}$ and $1 \mathrm{~b}$, enamine formation between aldehyde $\mathbf{1}$ and proline $\mathbf{4}$ is proposed as rate-determining. This is further supported in our current work by observation of a large primary isotope effect in reactions employing deuterium labeled propionaldehyde $\mathbf{1}$, where $\mathrm{kH} / \mathrm{kD}$ is found to be ca. 6.0 (see Supporting Information).

These combined observations allow a comprehensive explanation of the role of reaction products and additives in all of the proline-mediated reactions of eqs $1 \mathrm{a}-1 \mathrm{c}$ based on simple considerations of the rate-determining step in relation to the step affected by additives, as summarized in Scheme 1. If the role of the additive (or product) is to enhance the rate of enamine formation, then this will be manifested as a rate increase in reactions where this step is rate-determining (reactions $1 \mathrm{a}$ and $1 \mathrm{~b}$ ) but will not affect rate in a case where this step is in preequilibrium (reaction 1c). This conclusion is general regardless of the identity of the rate-enhancing species or the specific nature of the rate-enhancing interaction.

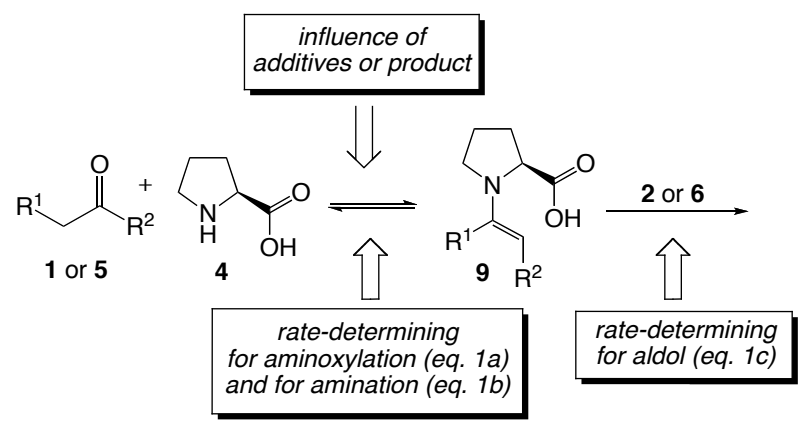

Scheme 1. Influence of additives and rate-determining steps for reactions $1 \mathrm{a}$ and $1 \mathrm{~b}$ compared to $1 \mathrm{c}$.
The concept shown in Scheme 1 is supported by a recent computational study revealing that enamine formation between dimethylamine and acetone is accelerated by methanol as a cocatalyst [18]. Scheme 1 is also in accordance with Seebach and Eschenmoser's [19] interpretation of the rate enhancement we reported in the reactions $1 \mathrm{a}$ and $1 \mathrm{~b}$, which they suggest may be attributed to acceleration of the transformation of an oxazolidinone to an enamine as the rate-determining step. In the proposal of Scheme 1, identical kinetic consequences result from the accelerated formation of the enamine regardless of the pathway this process takes.

Seebach and Eschenmoser have also argued for a prominent role for base catalysis in these prolinemediated transformations. Based on our earlier studies $^{9}$ implicating both substrate and product oxazolidinones as competent species in stoichiometric transformations of reaction $1 \mathrm{~b}$, they suggest that the basic functionality of the reaction products formed during the catalytic cycle of reactions $1 \mathrm{a}$ and $1 \mathrm{~b}$ could serve as the rate-enhancing species. They propose a cycle in which the enamine exists as a deprotonated species and suggest that the proposed role of the carboxyl proton in an intramolecular Bronsted acid activation of the electrophile might instead be fulfilled by other species in the system, citing the promoting role of $\mathrm{H}_{2} \mathrm{O}$ that has been suggested in other work. ${ }^{11}$ However, our previous studies of the aldol reaction argue against this proposal. First, we showed clearly that the intrinsic kinetic effect of water is in fact to suppress, not to promote, the rate of the catalytic reaction [6]; second, our reported deuterium isotope effect of $\mathrm{kH} / \mathrm{kD} \approx 2$ in the aldol reaction of eq $1 \mathrm{c}$ supports a role for the carboxyl proton in the ratedetermining enamine attack on the aldehyde 6 . Further experimental studies to investigate the role of added base in the reactions of eq. 1 are underway.

McQuade has studied the behavior of amine thiourea additives in reaction $1 \mathrm{a}$, attributing an observed rate enhancement to specific bifunctional interactions with oxazolidinone intermediates that promote their transformation to enamines, while proposing a separate rationale for product-enhanced rate [12]. They cited the lack of observed rate enhancement due to the additive in the same reaction using a proline tetrazole catalyst that cannot form oxazolidinones as support for a key role of these species. Direct observation of species within an operating catalytic cycle has not been reported for these reactions [20] and kinetic analysis alone cannot reveal the structure of the species involved or specific features of the interaction. However, our results indicate that rate enhancement due to additives is a more general phenomenon; it may occur in cases where such bifunctional interaction is not possible $\left(\mathrm{CH}_{3} \mathrm{OH}\right.$ and $\mathrm{CH}_{3} \mathrm{COOH}$, Figures 2 and 3$)$ and is lacking in some cases where oxazolidinone formation is possible (aldol reaction, eq 1c). Further, the kinetic profiles reported in Ref. 12 for the reaction of eq $1 \mathrm{a}$ with proline tetrazole resemble those where the rate- 
determining step is enamine attack on electrophile 2a rather than formation of the enamine. The proposal of Scheme 1 simplifies the mechanistic picture and, in addition, obviates the need to develop separate explanations for autoinductive and additive behavior, such as the "inner" and "outer" cycles proposed by McQuade [12].

In summary, a difference in the rate-determining step for proline-mediated aldol and aminoxylation reactions rationalizes why autoinductive behavior is observed in the latter but not the former, and also explains the rate-enhancing effect of additives including alcohols and acids [21]. Interactions between catalytic and additive or product species may result in rate enhancement, but only when such interactions influence steps of kinetic consequence in the catalytic cycle. The differences observed between the reactions of 1a-1c, even while they follow the same basic mechanistic framework, suggest that an understanding of the specific mechanistic constraints of each transformation will help in designing productivity-enhancing improvements. Detailed kinetic analysis of the catalytic cycle under operating conditions has been shown to be a useful tool for providing mechanistic information in these reactions. Further studies aimed at understanding the nature of the interactions between components in the catalytic cycle are underway.

\section{Experimental Section}

Reactions were carried out in an Omnical Insight reaction calorimeter, which allows continuous monitoring of the instantaneous enthalpy balance around the vessel. Further details are available in the Supporting Information.

\section{Acknowledgements}

Support from the EPSRC and from the Imperial College PharmaCat Consortium (AstraZeneca, GK, Pfizer) is gratefully acknowledged. Preliminary data collection by Dr S.P. Mathew is gratefully acknowledged. DGB acknowledges a Wolfson Research Merit Award. AM acknowledges a Fellowship from the Fundación Ramón Areces (Spain).

\section{References}

[1] B. List, R.A. Lerner, C.F. Barbas, III, J. Am. Chem. Soc. 2000, 122, 2395.

[2] a) P.I. Dalko, L. Moisan, Angew. Chemie Int. Ed., 2001, 40, 3726; b) P.I. Dalko, L. Moisan, Angew. Chemie Int. Ed., 2004, 43, 5138.

[3] C. Allemann, C.; R. Gordillo F.R. Clemente , P.H.Y. Cheong, K.N. Houk. Acc. Chem. Res. 2004, 37, 558.
[4] a) C.F. Barbas, III, A. Heine, G. Zhong, T. Hoffmann, S. Gramatikova, R. Björnestedt, B. List, J. Anderson, E.A. Stura, I.A. Wilson, R A. Lerner, Science 1997, 278, 2085.

[5] N. Zotova, L.J. Broadbelt, A. Armstrong, D.G. Blackmond, J. Bioorg. Med. Chem. Lett., 2009 (Sympoisum-in-Print), 19, 3934.

[6] N. Zotova, A. Franzke, A.Armstrong, D.G. Blackmond, J. Am. Chem. Soc., 2007, 129, 15100.

[7] S.P. Mathew, H. Iwamura, D.G. Blackmond, Angew. Chem. Int. Ed., 2004, 43, 3317.

[8] First reports of the aminoxylation reaction of eq 1a (although the autoinductive behavior was not noted in these studies): a) G. Zhong, Angew. Chem., Int. Ed. 2003, 42, 4247; b) S.P. Brown, M.P. Brochu, C.J. Sinz, D.W.C. MacMillan, J. Am. Chem. Soc., 2003, 125, 10808; c) Y. Hayashi, J. Yamaguchi, K. Hibino, M. Shoji, Tetrahedron Lett., 2003, 8293.

[9] a) H. Iwamura, S.P. Mathew, D.G. Blackmond, J. Am. Chem. Soc. 2004, 126, 11770-; b) H. Iwamura, D.H. Wells Jr., S.P. Mathew, M. Klussmann, A. Armstrong, D.G. Blackmond. J. Am. Chem. Soc. 2004, 126,16312.

[10] First reports of the $\alpha$-amination reaction of eq $1 b$ (although the autoinductive behavior was not noted in these studies): a) A. Bogevig, K. Juhl, N. Kumaragurubaran, W. Zhuang, K.A. Jorgensen, Angew. Chem. Int. Ed. 2002, 41,; 1790; b) B. List, J. Am. Chem. Soc., 2002, 124, 5656.

[11] a) A.I., Nyberg, A. Usano, P.M. Pihko. Synlett 2004, 11, 1891; c) P.M. Pihko, K.M. Laurikainen, A. Usano, A. Nyberg J.A. Kaavi, Tetrahedron, 2006, 62, 317; c) M. Lu D. Zhu, Y. Lu, Y. Hou, B. Tan, G. Zhong, Angew. Chem. Int. Ed. 2008, 47, 10187; c) C. Bolm, T. Rantanen, I. Schiffers, L. Zani, Angew. Chemie Int. Ed., 2005, 44, 1758.

[12] S.L. Poe, A.R. Bogdan, B.P.Mason, J.L. Steinbacher, S.M. Opalka, D.T. McQuade, J. Org. Chem., 2009, 74, 1574.

[13] S.P. Mathew, M. Klussmann, H. Iwamura, D.H. Wells, J.; A. Armstrong, D.G. Blackmond, Chem. Commun. 2006; 4291.

[14] D.G. Blackmodn, Angew. Chemie Int. Ed., 2009, 48,386 .

[15] We confirmed again that the observed rate enhancement cannot be attributed to increased proline solubilization over the course of the reaction by employing the following experimental protocol in all reactions reported here. A mixture of proline 4 and the additive add (either aldol product 7, $\mathrm{CH}_{3} \mathrm{OH}$, or $\mathrm{CH}_{3} \mathrm{COOH}$ ), was stirred in $\mathrm{CHCl}_{3}$ and the solution filtered at reaction temperature to remove any remaining solid proline. The filtrate containing only solution phase $\mathbf{4}$ and add was used as the base reaction in the series of aminoxylation reactions shown in Figures 2 and 3 in which 
increasing amounts of add were included. This excludes the possibility of that proline solution concentration could increase over time due to dissolution of the solid.

[16] S.P. Brown. PhD Thesis, California Institute of Technology, 2005, pp. 77-79. A shift from autoinductive to positive order kinetics for the reaction of eq 1a was was reported in this work when the reaction was carried out with 5 vol\% added $\mathrm{CH}_{3} \mathrm{OH}$ (corresponding to saturation according to Fig. 3). However, this effect was attributed to increased proline solution concentration due to dissolution of solid proline, which was monitored visually. The effect of lower $\left[\mathrm{CH}_{3} \mathrm{OH}\right]$ was not reported, nor were reactions compared under homogeneous conditions in order to deconvolute the dissolution effects from the intrinsic kinetic effects of the additive.

[17] Recent experiments show that added bases such as DBU also cause rate enhancement in the reaction of eq $1 \mathrm{~b}$ (A. Moran, M. Hughes, unpublished results). The role of DBU as an additive may be complicated by racemization of the reaction product $\mathbf{3 b}$. Further studies of the influence of added bases are underway.
[18] M. P. Patil, R.B. Sunoj, J. Org. Chem., 2007, 72, 8202.

[19] D. Seebach, A.K. Beck, D.M. Badine, M. Limbach, A. Eschenmoser, A.M. Treasurywala, R. Hobi, W. Prikoszovich, B. Linder, Helv. Chimia Acta, 2007, 90, 425.

[20] Yamamoto has given evidence that product selectivity in the stoichiometric reaction of preformed pyrollidine enamines with electrophiles may be influenced by acidic chiral additives. N. Momiyama, H. Yamamoto, J.Am. Chem. Soc., 2005, 127, 1080 .

[21] We are indebted to an anonymous reviewer from a separate manuscript submission who first suggested a rationalization based on differences in ratedetermining step. 
A Coherent Mechanistic Rationale for Additive Effects and Autoinductive Behavior in ProlineMediated Reactions

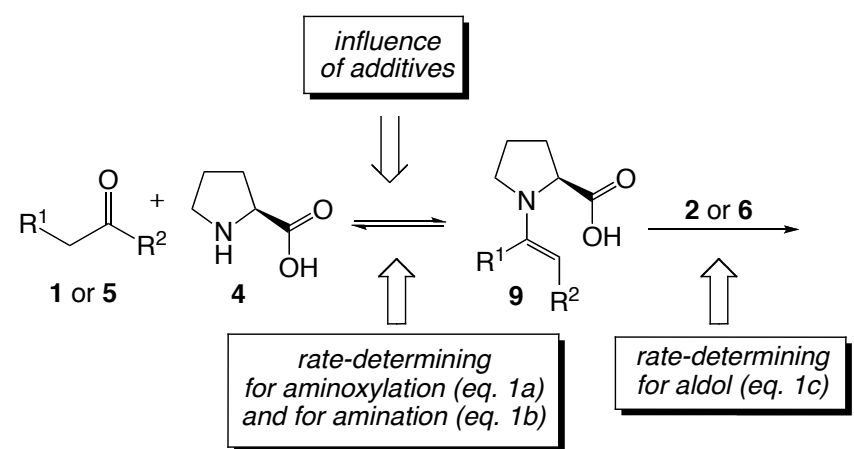

Adv. Synth. Catal. 2008, 350, Page - Page

Natalia Zotova, ${ }^{\mathrm{a}}$ Antonio Moran, ${ }^{\mathrm{b}}$ Alan

Armstrong $^{\mathrm{b} *}$, and Donna G. Blackmond ${ }^{\mathrm{a}, \mathrm{b} *}$

and for amination (eq. 1b) 